\title{
The Effect of Immediate Correction of EFL Learners' Mispronunciation in Enhancing Classroom Discussion
}

\author{
Amir Abdalla Minalla \\ Department of Languages and Translation, University of Tabuk / Saudi Arabia. \\ E-mail: Amirdarnile@gmail.com
}

Received: July 11, 2019 Accepted: August 15, 2019 Published: August 17, 2019

doi: 10.5296/ire.v7i2.15286 URL: https://doi.org/10.5296/ire.v7i2.15286

\begin{abstract}
The studies that viewed in this study showed that breaking students' communication has a negative effect on their interaction. Although, the tremendous efforts that have been exerted in order not to break the flow of EFL learners' verbal communication, EFL teachers are forced to do it i.e. necessity of immediate correction of some errors. This study is to examine whether immediate correction of mispronounced key utterances of interlocutors could enhance a classroom discussion. Analysis of collected data revealed that Group1's participants who dealt with the conversation in which its interlocutors were immediately corrected in their mispronouncing key utterances significantly outperformed Group2's participants who dealt with the conversation in which its interlocutors were corrected with some delayed i.e. after finishing their speech. Hence, immediate correction of mispronounced key utterances positively enhances classroom discussion more than delayed correction.
\end{abstract}

Keywords: key utterance, discussion, immediate correction, delayed correction

\section{Introduction}

The prevalent trend of designing EFL classes is to involve its students in an interesting meaningful interaction. Process of learning a language inevitably involves the making of mistakes (Brown, 2000). Teachers as possible avoid not to break the flow of students' verbal communication, at least up to finishing a speech, i.e. completing an idea. Thus, if the pronunciation is poor, neither grammar nor vocabulary will help us in comprehending an utterance. In spite of interrupting students' communication is unwelcome technique, still necessary particularly, when the erroneous items negatively affect comprehending an intended idea. Therefore, EFL learners who master English pronunciation probably better understand what suggested for them even if they make errors in other areas, in contrast of those who with a weak background in terms of pronunciation unlikely understand what 
suggested for them properly, even if their grammar knowledge was perfect (Gilakjani, 2016). Thus, the study is to investigate an immediate correction of incorrect pronunciation and its influence in a discussion of the classroom.

Pronunciation difficulties of EFL Arabic learners referred to the different factors such as the different linguistic families of English and Arabic consequently the difference in the Sound Systems. For instance, to the learner, written English is not always a reliable guide to pronunciation, and they are often misled by the graphic representation of sounds this based on the fact that in contrast to the irregular spelling of English, Arabic spelling is overwhelmingly regular (Kharma \& Hajjaj, 1997). Arab learners, like many other L2 learners, have difficulty distinguishing some vowels and some consonants as well. Even if the deviations they make from Received pronunciation (RP) do not hinder intelligibility, it is desirable to cope with those problems for the purpose of enhancing understandability (Chouchane, 2016). Some English consonants sounds do not exist in the Arabic like /p/,/y/ and /v/ and even these consonants, which seem similar to some Arabic consonants like /t/ or / $/$, are not identical but different in the manner and even in the place of articulation (Abdulwahab, 2015). Thus, if the learners cannot utter the correct version of a word then they are not able to communicate correctly (Gilakjani, 2016). Communication problems are more likely to be caused by vocabulary and pronunciation issues rather than by grammar ones (Mackey et al., 2016 cited in Kerr (2017). Without adequate or intelligible pronunciation often make it hard for the speakers to make themselves understood or even make them misunderstood and listeners puzzled (Jing, Xiaodong \& Yu, 2016; Tejeda \& Santos, 2014).Thus, Feedback on pronunciation leads to greater learning gains (Lyster et al., 2013 cited in Kerr,2017). Leaving pronunciation errors incorrected break learners` interaction (Gilakjani, 2016.)

Many studies have conducted for investigating the effect of breaking students' interaction flow particularly for the purpose of correction. From one hand, research studies like (Martínez, 2006; Mousavi \& Gorjian, 2018; Bai, 2006 cited in Jing, Xiaodong, \& Yu, 2016; Walker, 1973; Burt, 1975; Horwitz \& Cope, 1986; Young, 1991 cited in Martínez, 2006) show that even for the purpose of correction, interrupting the student before finishing their utterance has a negative effect that beside impede comprehension and make students feel embarrassed and discouraged and lead to students' withdrawal from learning. From the other hand the effect of immediate correction on learners' interaction have been investigated by (Mousavi \& Gorjian, 2018; Rahimi \& Dastjerdi, 2012) their studies show that correcting learners immediately could be demotivating and it could end up killing their self-confidence. Consequently, it negatively affect the fluency of learners particularly if the aim of learning language is fluency.

\section{Methodology}

\subsection{Participants}

The study's participants consisted of twenty males EFL Saudi learners aged between 18 and 20, first year university students, Tabuk University, Saudi Arabia. The participants divided into two groups, Group1 and Group2, each one included 10 participants.

\subsection{Procedures}

The study used an observation checklist as a tool for data collection. For checking an 
observation checklist items, participants of both groups were exposed to listen to two different conversations that intentionally designed to the purpose of this study. The participants of Group1 dealt with the conversation ' $A$ ' in which their teachers immediately corrected its interlocutors when they mispronounced key utterances. Participants of Group2 dealt with the conversation ' $\mathrm{B}$ ' in which the correction of its interlocutors was done with some delayed, i.e. after finishing their speech. Testing items of the observation checklist applied for each group in its own.

\section{Data Analysis}

The study aims to identify whether the method of immediate correction was supportive or impeded for classroom discussion. Collected data were to check whether the performance of Group1 or Group2 was supportive or impeded to the classroom discussion. Each item in the checklist was analyzed and compared in both groups. Testing items of the observation checklist in the class was through discussion questions that inspire analysis, synthesis, interpretation and critical thinking. Analysis of five successive sessions of classroom discussion has come with as follows:

1) Awareness of the key points that proposed in the conversation

Majority of Group1's participants $(87 \%)$ positively interacted with the discussion questions that intend to check the key points of the conversation. Responses of Group2's participants to the key points questions quit varied, as (55\%) of the Group2's participants could not feedback on what is related to the key points, $(38 \%)$ of the participants only provides some aspects concerning key points while only (7\%) who were able of identifying key points of the conversation. Thus, for classroom discussion, immediate correction of mispronounced key points helps participants getting intended key points in contrast to delayed correction.

2) Interest of participation in the classroom discussion

(70\%) of Group1's participation in the discussion based on its participants' initiative while (30\%) of Group2's participation based not on its participants' initiative. In contrast, Group2 in which $(80 \%)$ of its participation has not come based on its participants' initiative. From item 1 and 2, the participants those who with well aware of the key points were interested in taking part in the classroom discussion.

3) Confusion about what suggested for the classroom discussion

The effective interaction of all Group1's participants reflected their awareness of what proposed. The majority of Group2's participants (85\%) discussed the key points of the discussion confusingly while (15\%) of participants assuredly attempted the key points. Therefore, awareness of Group's participants about the key ideas of the discussion enabled them of interacting assuredly.

4) Sharing ideas of the conversation in the classroom discussion

Majority of Groupl's participants $(80 \%)$ were able to share the ideas of the conversation with their partners while only (20\%) of Group2's participants enabled of exchanging the ideas with their partners. Thus, Group1's participants were more capable of sharing their ideas with their partners than Group2's participants.

5) Appropriateness of participants' contribution in the discussion 
(90\%) of Group1's participants effectively enriched the discussion with meaningful interrelated ideas. In other words, they dominate the discussion. Only (20\%) participants of Groups 2 contributed to the discussion. It means that participants' awareness of the main ideas enabled them to involve in the discussion in a wide range.

\section{Conclusion}

Many recent studies has proved that immediate correction has a negative effect on students' performance. However, in this study immediate correction of key utterances in the classroom discussion has proved its effectiveness and enhancement for the discussion. Therefore, immediately correcting mispronounced key utterances of the interlocutors during classroom discussion is more helpful in enhancing discussion in a wide range for all participants.

\section{References}

Abdulwahab, H. A. (2015). Difficulties of English Pronunciation Encountered by Saudi Learners. Unpublished M.A. Thesis. Open University of Sudan, Khartoum, Sudan.

Burt, M. (1975). Error analysis in the adult EFL classroom. TESOL Quarterly, 9(1), 53-63. https://doi.org/10.2307/3586012

Brown, H. D. (2000). Principles of language learning and teaching (4th ed.). New York: Longman.

Chouchane, A. (2016). Pronunciation Difficulties for Arab Learners of English. Global English-oriented Research Journal.

Gilakjani, A. (2016). The Significance of Pronunciation in English Language Teaching. International Journal of Research in English Education, 1(1).

Jing, H., Xiaodong, H., \& Yu, L. (2016). Error Correction in Oral Classroom English Teaching. English Language Teaching, 9(12). https://doi.org/10.5539/elt.v9n12p98

Kharma, N., \& Hajjaj, A. (1997). Errors in English among Arabic speakers: Analysis and remedy. BeirutL Librairie du Liban.

Kerr, P. (2017). Giving feedback on speaking. Part of the Cambridge Papers in ELT series. Cambridge: Cambridge University Press.

Martínez, S. G. (2006). Should we correct our students errors in 12 learning? Journal of Research and Innovation in the Language Classroom.

Mousavi, K., \& Gorjian, G. (2018). Using Error Correction in Teaching Oral Production to Iranian EFL Learners. Journal of Applied Linguistics and Language Learning, 4(2), 21-29.

Rahimi, A., \& Dastjerdi, H. (2012). Impact of Immediate and Delayed Error Correction on EFL Learners' Oral Production: CAF. Mediterranean Journal of Social Sciences, 3(1).

Tejeda, A., \& Santos, N. (2014). Pronunciation Instruction and Students' Practice to Develop Their Confidence in EFL Oral Skills. PROFILE, 16(2). https://doi.org/10.15446/profile. v16n2.46146

Walker, J. L. (1973). Opinions of University Students about Language Teaching. Foreign Language Annals, 7, 102-05. https://doi.org/10.1111/j.1944-9720.1974.tb00088.x 


\section{Macrothink}

International Research in Education

ISSN 2327-5499

2019, Vol. 7, No. 2

\section{Copyright Disclaimer}

Copyright reserved by the authors.

This article is an open-access article distributed under the terms and conditions of the Creative Commons Attribution license (http://creativecommons.org/licenses/by/3.0/). 